\title{
Urdimento
}

\section{O ESPÍRITO TRAVESSO NA MÍMICA CORPORAL DRAMÁTICA DE ETIENNE DECROUX}

\author{
George Mascarenhas ${ }^{1}$
}

\section{Resumo}

Este artigo tem como propósito abordar os princípios técnicos e estéticos da mímica corporal dramática com relação à utilização de procedimentos cômicos em sua criação artística. Através de uma análise histórica, o texto destaca as características principais da mímica corporal dramática de Etienne Decroux e da pantomima, para mostrar os diferentes percursos dos dois estilos com relação à comicidade. Utilizando como base os conceitos de Bergson de mecanicidade e inadaptabilidade, o artigo discute a presença da comédia na técnica e repertório da mímica corporal dramática decrouxiana.

Palavras-chave: mímica corporal dramática, procedimentos cômicos, mecanicidade, inadaptabilidade.
Abstract

The purpose of this article is to approach the technical and aesthetical principles of dramatic corporeal mime in relation to the comic procedures in its artistic creation. Through a historical analysis, the text highlights the main characteristics of Etienne Decroux's corporeal mime and classical pantomime to show the distinct ways in which both styles deal with comedy. Based on Bergson's principles of mechanical rigidity and inadaptability, the article discusses the presence of comic procedures in the technique and repertoire of corporeal mime.

Keywords: dramatic corporeal mime, comic procedures, mechanical rigidity, inadaptability.

Em muitas situações, ao me apresentar como mímico, escuto o comentário cheio de surpresa, seguido, freqüentemente, de uma solicitação: "Vocêé mímico? Oh, faça aí uma mímica!". A solicitação do interlocutor se refere, em geral, a uma ação de natureza supostamente espetacular, surpreendente ou cômica, associada à manipulação de objetos invisíveis, típica da pantomima, como tomar chá em uma xícara "invisível" ou fazer algo que possa servir de jogo de adivinhação.
${ }^{1}$ George Mascarenhas

é ator e diretor teatral formado pela École de Mime Corporel Dramatique (Londres), Mestre em Artes, Doutorando em Artes Cênicas (PPGAC/ UFBa), professor do Curso de Artes Cênicas da Faculdade Social da Bahia. E-mail: georgemascarenhas @hotmail.com 


\section{Urdimento}

${ }^{2}$ Todas as citações em língua estrangeira têm tradução nossa. No original: "And this pantomime seemed to me to be systematically comic, even before one knew what the subject was. And there we have it. That said, I've let you see my tastes a bit, even before getting on to the stage" (DECROUX, 1978: 9)

${ }^{3}$ Os termos drama e dramático são aqui utilizados como designação do gênero poético. As formas dramáticas históricas são indicadas neste artigo por adjetivação. Drama sério refere-se aqui à forma dramática que trata de temas sérios de modo sério.

4"II n'avait pas besoin de traiter un sujet comique, il était déjà comique."(DECROUX, 2003: 59)
Para evitar uma longa explicação de natureza teórica que aborde a distinção entre a mímica corporal dramática de Etienne Decroux (MCD), técnica que pratico, e a pantomima, apenas dou um sorriso amarelo, na maioria das vezes... Outras vezes, digo sucintamente: "não, não é esse tipo de mímica..." Raramente, nessas circunstâncias, é possível explicar que, com a mímica corporal dramática, não posso retirar um coelho invisível de uma cartola invisível, porque o estilo, o direcionamento artístico e estético apontam para outro caminho, seguramente oposto àquele identificado com a pantomima.

A idéia deste tipo de número parece estar bem distante dos princípios da MCD, o que torna a reação do interlocutor, quase invariavelmente, uma expressão de frustração. Afinal, de que serve a mímica que não possa nos fazer rir entre um salgadinho e outro? E, de outro modo, como o caminho estético da mímica corporal dramática de Etienne Decroux dialoga com a perspectiva do cômico?

Em primeiro lugar, é preciso notar que o desejo daquele interlocutor caracteriza uma das principais objeções de Etienne Decroux à pantomima, técnica que declaradamente abominava:

E esta pantomima me parecia ser sistematicamente cômica, mesmo antes de se saber qual era o tema. E era assim que ela existia. Era como se ela dissesse 'eu deixo vocês sentirem um pouco do meu sabor', mesmo antes de entrar no palco. (DECROUX,1978: 9) ${ }^{2}$

Na concepção de Etienne Decroux, uma arte deve ser "séria” antes de ser divertida, ou seja, deve conter a possibilidade de tratar de temas graves, de atingir a emoção do espectador em diversos níveis, de abordar conteúdos humanos complexos como em um drama sério ${ }^{3}$ ou com um tratamento épico ou mesmo através da comédia, mas nunca a priori com procedimentos exclusiva ou predominantemente cômicos, como ele acredita ser o caso da pantomima. Para Decroux, a pantomima "não tinha necessidade de tratar de um assunto cômico; ela já era cômica por si só”. (DECROUX, 2003: 59)"

De fato, um olhar sobre a história da mímica, como gênero teatral, e especialmente da pantomima, como estilo, desde sua origem na antigüidade clássica, mostra o quanto esta arte é associada ao divertimento, ao jogo cômico ou ao alívio da tensão no entreato de um melodrama ou por outro lado, ao lirismo sentimental, mantendo, de todo modo, o espírito popular que a manteve presente, durante muito tempo, nas feiras e praças públicas.

Em sua origem na antiga Roma, enquanto o termo mímica era utilizado para designar quase todos os tipos de drama diferentes dos gêneros clássicos (tragédias, comédias, dramas satíricos) e não necessariamente implicava em 


\section{Urdimento}

atuação silenciosa, a pantomima era um estilo voltado para a encenação de fábulas nas quais o pantomimus representava sem palavras as ações que eram narradas pelo coro, acompanhado por músicos, versando em geral sobre temas morais, como o adultério, ou ridicularizando situações políticas, sociais e religiosas (MASCARENHAS, 2007).

Muitas vezes, os temas eram tratados com fortes cores obscenas e grotescas, o que contribuiu para o surgimento de grandes antagonismos de natureza moralista. Nos primeiros séculos da dominação cristã no império romano,

Os cristãos tinham dificuldade em entender porque os mímicos satirizavam seus próprios deuses pagãos e se sentiram ultrajados quando o Cristianismo começou a ser atacado. Ouvimos, por exemplo, sobre uma peça de mímica que mimicava o batismo de um moribundo em pânico com a salvação. (WILES, 1997: 63)

O contexto de obscenidade, explorado pelo viés cômico, ainda segundo Wiles, era um modo de manter uma certa liberdade no discurso, permitindo a expressão de idéias e sentimentos contrários ao regime instituído, já que essas peças centradas no ator, total ou parcialmente improvisadas, podiam escapar mais facilmente da censura do que as formas de teatro com texto escrito.

Ao longo da história, o cômico manteve-se como o traço predominante do estilo, embora nem sempre com esse caráter de transgressão. A pantomima absorveu também características de um lirismo ingênuo sobretudo a partir do trabalho de Jean-Gaspard Deburau (1796-1846), mímico francês que se consagrou na figura do Pierrot e iniciou a tradição da pantomima branca moderna, com os artistas de rosto pintado. Deburau, imortalizado no filme "Les enfants du paradis" (O boulevard do crime), de Marcel Carné (1945), "mudou o Pierrot [originalmente Pedrolino, zanni da Commedia dell'Arte] de um velhaco cínico e grotesco em um camarada poético e trouxe uma expressão pessoal para a fantasia, acrobacia, melodrama e encenações espetaculares que caracterizavam as pantomimas do século XIX” (LUST, 2001)

De acordo com Innes (1997), foi a imagem farsesca e macabra do Pierrot pálido de Deburau, interpretado por Jean-Louis Barrault no filme de Carné, que se tornou a base para a criação do Bip de Marcel Marceau, responsável pela popularização do estilo no mundo no século XX, com sua camiseta listrada e o rosto melancólico pintado de branco. Explorando a tradição lírica de Deburau e, mais freqüentemente, o caráter cômico despertado pelo ilusionismo a partir da manipulação de objetos "invisíveis", encontramos no trabalho de Marceau poucas experiências com números que abordam temáticas mais densas ou de

\footnotetext{
${ }^{51}$ Christians found it hard to understand why mime actors made fun of their own pagan gods, and were outraged when Christianity came in for attack. We hear, for example, of a mime play which mimicked the baptism of a dying man panicked about salvation". (WILES, 1997: 63)
}

\footnotetext{
5 "He changed Pierrot from a cynical, grotesque rogue into a poetic fellow and brought a personal expression to the fantasy, acrobatics, melodrama, and spectacular staging that characterized nineteenth-century pantomimes" (LUST, 2001)
} 


\section{Urdimento}

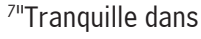
mon fauteuil, je vis un spectacle inouï. C'était du mime et des sons. Le tout sans une parole, sans un maquillage, sans un costume, sans un jeu de lumière, sans accessoires, sans meubles et sans décor."(DECROUX, 1994: 18)

8"Le mime, pensaije, a mieux à faire que de compléter un autre art." (DECROUX, 1994 : 34) forma aproximada ao drama sério, dentre os quais se destaca Jeunesse, Maturité, Vieillesse et Mort (Juventude, Maturidade, Velhice e Morte), na qual o mímico representa as diferentes fases da vida em uma marche sur place (caminhada no mesmo lugar, sem deslocamento).

Em oposição declarada e radical a essa tendência, muito em virtude da visão de mundo e arte e das aptidões e desejos do seu criador, bem como do momento histórico do seu surgimento, encontra-se a mímica corporal dramática de Etienne Decroux.

O início da construção da mímica corporal dramática na primeira metade do século $\mathrm{XX}$, acontece em um período marcado pelos grandes movimentos e manifestos modernistas e pela utilização de mímica e máscaras como suporte de preparação para o teatro dito de texto - centrado na literatura dramática -, a exemplo das experiências de Jacques Copeau na École du Vieux Colombier, onde Decroux estudou.

Em 1923, o jovem anarquista que desejava se tornar orador político, começou a freqüentar a École du Vieux Colombier que oferecia cursos gratuitamente para quem se dispusesse a trabalhar como figurante nas peças realizadas no teatro de mesmo nome. Apesar de seu firme propósito políticoideológico, Decroux acabou seduzido por uma experiência determinante em sua trajetória: uma demonstração de máscara neutra, na qual descobriu o princípio gerador de sua mímica corporal. "Tranqüilo em minha poltrona, eu vi um espetá $\neg$ culo prodigioso. Era mímica e sons. Tudo sem uma palavra, sem maquiagem, sem um figurino, sem um jogo de luz, sem acessórios, sem móveis e sem cenário.” (DECROUX, 1994: 18)7

Cansado das formas de teatro convencionais do seu tempo, Etienne Decroux começou a dialogar com a proposição da supermarionete de Edward Gordon Craig e investigar uma forma de teatro centrada no trabalho corporal do ator: "A mímica, eu pensava, tem mais a fazer do que completar uma outra arte” (DECROUX, 1994: 34) ${ }^{8}$.

A técnica decrouxiana nasce então com uma vocação anti-naturalista, um desejo de ser mais do que uma técnica de base para o teatro de texto e uma clara distinção de outros estilos de mímica, particularmente, da pantomima. Esses princípios de algum modo o levaram a radicalizar a lógica da arte séria, dedicando-se muito pouco à exploração do cômico em seu repertório. $\mathrm{O}$ conceito de arte séria, vale ressaltar, não é uma oposição ao gênero cômico - até porque Decroux era um grande apreciador da comédia e de nomes como Molière e Chaplin -, mas uma atitude contrária ao desejo exclusivo da provocação ou da expectativa do riso a priori, ou da ilustração característica do lirismo pantomímico.

0 espírito travesso na mímica corporal dramática... George Mascarenhas.

Dezembro 2008 - № 11 
Segundo Corinne Soum, última assistente do mestre francês, ao lado de Steven Wasson, em conferência proferida no ECUM-2002, em Belo Horizonte, por esse traço distintivo em seu trabalho, Decroux tirou a mímica da rua para dar-lhe o tratamento de um drama sério ou com influência épica, eliminando sua natureza de comicidade a priori. O desejo de tratar do homem em sua essência prometeica, grandiosa, mítica é talvez a principal razão pela qual encontram-se poucas situações de exploração da comicidade no repertório de peças e figuras (exercícios cênicos de curtíssima duração) criadas por ele.

Para Decroux (1978), um homem que se levanta é emblema da humanidade inteira, no que ela tem de luta, paixão e sofrimento - daí a imagem do caráter prometeico. Não à toa, encontramos em sua obra referências à mitologia e a atos heróicos ou de grande valor moral, a exemplo das peças Le combat antique (O Combate Antigo) e La vie primitive ( $A$ vida primitiva) e das figuras de estilo La caresse sur le dos de Venus (A Carícia nas Costas de Vênus) e Le fils prodigue (O Filho Pródigo).

A busca de Decroux volta-se para o homem em essência, cuja luta, expressa corporalmente através da exposição do conflito com a gravidade terrestre, é resultado das diversas lutas internas do pensamento. Ao dirigir sua técnica para a fisicalização do pensamento, Decroux oferece à mímica um caráter fortemente abstrato, radicalizado em peças como La Meditation ( $A$ Meditação), Le Prophète (O Profeta) ou La Femme Oiseau (A Mulher Passarinho), afastando-se ainda mais da exploração da comicidade.

Interessa, em primeiro lugar, a transposição cênica denominada por ele de "retrato do invisível", a criação de imagens visíveis do pensamento, das lutas e aspirações humanas presentes no cotidiano mais prosaico ou nas molduras mais míticas, em oposição a uma perspectiva ilustrativa ou representativa.

Do ponto de vista da técnica propriamente, Decroux brinca com a lógica aparente ou contraditória das linhas, do peso e do volume corporal, em uma estrutura muitas vezes fragmentada, afastando-se dos princípios neo-aristotélicos de construção dramatúrgica, para criar sequências de ação interrompida, e, poderíamos dizer, editada: ao escorregar em um pedaço de sabão, a Lavadeira (La Lessive, 1931), que acabou de estender suas roupas em um varal, desliza para o fim do seu dia e retira as roupas já secas.

A preocupação com a fábula desaparece, permanecendo apenas como fonte de inspiração para a criação artística. A "historinha” contada em cena está em segundo plano, ofuscada pelo desejo de expressar o mundo invisível, imaterial, o pensamento e o sonho de um homem em luta, restando, em alguns casos, poucos pontos de referência identificáveis de fábula unívoca.

Dezembro $2008-N^{\circ} 11 \quad 0$ espírito travesso na mímica corporal dramática... George Mascarenhas. 


\section{Urdimento}

9"Les mauvaises nouvelles, les bonnes nouvelles provoquent dans le corps des manifestations différentes, ce sont des dynamo-rythmes. La passion c'est d'abord le dynamo-rythme. C'est un luxe qu'un animal puisse se déplacer et il y a des animaux qui ne se déplacent pas du tout. Comme seules manifestations ils ont la contraction et le relâchement: c'est du dynamo-rhytme. Oui, le dynamo-rythme, c'est ce qui exprime le plus inténsement la passion". (DECROUX, 2003: 129)
Na MCD, é a ação física que gera novas ações. Sai a causalidade da ação e reação psicológica ou factual para entrar em cena a causalidade corporal: assim como o "peso decisivo" faz a balança pender para um lado, o "peso decisivo" de um braço pode fazer todo o corpo inclinar-se naquela direção.

De fato, esta ênfase sobre o corpo é determinante na construção ar tística na MCD, não importa o tratamento dado à ação ou o gênero escolhido. Assim, comédia ou drama sério se dão no corpo, não necessariamente em silêncio, pela causalidade física. Pode-se observar no entanto uma tendência não-cômica em sua origem, tanto no que se refere aos princípios fundamentais de natureza filosófica quanto no uso dos procedimentos técnicos propriamente ditos.

Guy Benhaim (2003) fala da imobilidade presente na técnica como sendo o ponto de deslize da MCD em direção ao drama sério. A imobilidade, como procedimento artístico marcante do estilo da mímica corporal dramática reportase à expressão de uma reflexão, um pesar, uma luta interna do homem: no ato da meditação, da hesitação, da memória, do devaneio, há uma parada, uma suspensão interna. Essa parada mental é expressa corporalmente, na MCD, através da imobilidade, da interrupção da ação física, de uma parada literal no movimento.

No entanto, embora o princípio da imobilidade seja inegável e de máxima importância na técnica, o próprio Decroux privilegia o dínamo-ritmo (conjunto de combinações específicas na MCD de força e velocidade da ação), como sendo a alma do movimento.

As más notícias, as boas notícias provocam no corpo manifestações diferentes: são os dínamo-ritmos. A paixão é, antes de tudo, dínamo-ritmo. É um luxo que um animal possa se deslocar e há animais que não se deslocam de modo algum. Como manifestações únicas eles têm a contração e o relaxamento: isso é dínamo-ritmo. Sim, o dínamo-ritmo é o que exprime mais intensamente a paixão. (DECROUX, 2003: 129) ${ }^{9}$

Neste sentido, o tempo, o ritmo e a dinâmica em que uma ação acontece a empurram em direção ao drama sério ou à comédia. Assim, o movimento de um único dedo, através da causalidade corporal, pode levar o corpo inteiro ao chão, mas o efeito (cômico ou sério) dependerá em grande parte do dínamoritmo em que for realizada a queda. Não é, portanto, apenas a imobilidade o procedimento técnico que mais aproxima a MCD do drama sério, mas o dínamoritmo aplicado à situação. A própria imobilidade pode ser um procedimento cômico, na medida em que seja criada uma incongruência entre a situação e o tempo em que se permanece imóvel.

0 espírito travesso na mímica corporal dramática... George Mascarenhas.

Dezembro 2008 - № 11 


\section{Urdimento}

Ao refletir sobre o cômico, Decroux entende que a comicidade se encontra na mecanização com a qual uma ação é desempenhada: "O homem é cômico quando é mecânico. O que caracteriza a mecanicidade, é que ela não se adapta e o homem é cômico quando é inadaptado" (DECROUX, 2003: 193) ${ }^{10 .}$

Esta reflexão tem um forte ponto de aproximação com o pensamento de Henri Bergson, para quem o riso advém, justamente, do automatismo e da inadaptabilidade, já que, nas situações cômicas, se tem "a impressão de estar, simultaneamente, diante de uma pessoa e de um mecanismo” (MENDES, 2006: 90).

Em O Riso - Ensaio sobre a Significação do Cômico, texto publicado pela primeira vez em 1900, Bergson ilustra a noção de automatismo cômico utilizando-se de dois exemplos: a queda na rua e a "pegadinha" do escritório.

No primeiro caso, um homem que corre na rua tropeça em uma pedra que estava no meio da calçada e cai, sendo objeto de riso de passantes. Segundo Bergson (2005), o riso acontece não porque houve uma mudança brusca de atitude, mas porque esta mudança aconteceu involuntariamente. É provável que ninguém risse se o sujeito tivesse a intenção de sentar-se na calçada. E para evitar a queda, bastaria que o corpo se desviasse, se adaptasse à situação drummondiana de que no meio do caminho havia uma pedra, havia uma pedra no meio do caminho.

No segundo caso, um brincalhão altera os objetos de alguém que se dedica a suas ocupações com uma "regularidade matemática" e o faz colocar sua pena em um pote de lama, sentar-se no vazio e, portanto, cair no chão, porque a posição da cadeira foi alterada, etc. Bastaria uma interrupção por parte da vítima da "pegadinha", um momento de imobilidade, uma parada, para que as ações fossem reorientadas para o percurso desejado originalmente. Todavia, a imobilidade que corrigiria o desvio poderia se tornar o próprio procedimento cômico, caso a personagem se mantivesse em seu trajeto matemático, sem os necessários ajustes, mesmo após o tempo de reflexão. E ainda assim, tudo dependeria do dínamoritmo com o qual a parada fosse realizada e a ação retomada.

Nos dois casos, de acordo com Bergson, é a obstinação corporal, o automatismo, que faz com que o sujeito mantenha uma linha reta na corrida ou continue trabalhando com objetos truncados. "As atitudes, gestos e movimentos do corpo humano são risíveis na exata medida em que este corpo nos faz pensar em uma simples mecânica." (BERGSON, 2005: 28)

Mesmo considerando a importância do aspecto do automatismo na construção cômica, encontramos no repertório da MCD um exemplo que parece contradizer o pensamento de Bergson e a própria reflexão de Decroux.

\footnotetext{
10"L'homme est comique quand il est mécanique. Ce qui caractérise la mécanique, c'est qu'elle ne s'adapte pas et l'homme est comique quand il est inadapté." (DECROUX, 2003: 193).
}

11"Les attitudes, ges-
tes et mouvements
du corps humain sont
risibles dans l'exacte
mesure où ce corps
nous fait penser à
une simple mécanique".
(BERGSON, $1924: 28$ ) 


\section{Urdimento}

Em L'usine (A fábrica), peça decrouxiana de 1946, homens estão trabalhando. Ouvem-se o apito e sons mecânicos. As ações humanas são desempenhadas com o máximo de automatismo. O efeito estético é sempre mais impressionante quanto mais precisamente forem desempenhadas as ações pelo grupo. $\mathrm{O}$ mímico não representa uma máquina. $\mathrm{O}$ mímico é a imagem do homem que trabalha na fábrica e cujas ações repetitivas em série o fazem fundir-se com a máquina, pela natureza do seu trabalho. $\mathrm{O}$ automatismo de $A$ Fábrica revela uma espécie de crítica - reflexo da ideologia política de Etienne Decroux - às longas jornadas de trabalho massacrante dos operários nas fábricas das décadas de 30/40.

Apesar disso, diferentemente do tratamento dado ao tema, por exemplo, por Chaplin em Tempos Modernos (1936), o resultado estético de A Fábrica não tem um efeito cômico. Falta-lhe ainda o traço de inadaptabilidade, observado aqui como um aspecto distinto da mecanicidade.

O homem de A Fábrica, embora concentrado no automatismo de suas ações, é integralmente adaptado a elas e as desempenha com uma precisão matemática. No único momento lírico da peça, alusão ao intervalo entre as jornadas, o homem descansa e devaneia, ao contrário da personagem chapliniana que continua apertando parafusos nos botões da saia de uma funcionária da fábrica, sem conseguir despregar-se do automatismo imposto pelo trabalho. $\mathrm{Na}$ peça decrouxiana, ao fim do tempo de descanso, o trabalho é retomado com as ações em série. $\mathrm{O}$ desvio em Chaplin é a continuidade do automatismo quando ele não seria mais necessário. Em $A$ Fábrica, não há desvios e, portanto, mesmo na presença do automatismo mais absoluto, não há comédia.

Mecanicidade e inadaptabilidade aparecem juntas, no entanto, em outra peça de mímica corporal dramática, L'esprit malin ( $O$ espírito travesso), criada em 1946 por Maximilien Decroux e Eliane Guyon, sob a orientação do mestre Decroux. Na peça, um homem é assombrado por um espírito. Sentado em sua cadeira, vê, com surpresa, que seus braços (são os do "espírito travesso") fazem movimentos involuntários complexos. Pára, como se se perguntasse como ou porquê sua mão está fazendo isso, mas continua o seu trajeto de ações. Um terceiro braço surge e as situações construídas são acompanhadas com um ar de espanto investigativo, um olhar absoluto sobre a situação. O homem acende um cigarro e vê surgirem outros três e, ainda assim, busca uma explicação. $\mathrm{Na}$ lógica da cena, o "Esprit Malin" se esconde e se revela como e quando deseja e o "assombrado", apesar de um pouco intrigado, continua agindo como se nada estivesse acontecendo.

O tema, tantas vezes abordado pelo cinema, bem poderia ser tratado em $O$ espírito travesso com uma atmosfera sombria, como uma peça de terror. Mas, no caso da peça decrouxiana, o dínamo-ritmo que determina a alma 
interpretativa do movimento confere à situação um sentido de jogo. O fantasma não está ali para acertar pesadas contas cármicas passadas, nem para aterrorizar o homem. Ele volta para brincar.

O espírito travesso constitui-se, assim, em uma peça exemplar de comicidade na mímica corporal dramática de Etienne Decroux, na medida em que investe na combinação do automatismo e da inadaptabilidade, calcada na elaboração das ações e do dínamo-ritmo, oferecendo uma personagem que mantém uma relação continuada com seu "cotidiano", mesmo diante de uma situação inusitada.

Como procedimento cômico, O espírito travesso joga com uma "lógica trapaceira e auto-suficiente" (MENDES, 2006: 90), assim como um Chaplin que, disfarçado de abajur, consegue esconder-se do policial. O espectador é levado para o lugar de uma outra realidade na qual tudo parece ser possível, sendo o jogo corporal dos atores o elemento determinante para deflagração do riso.

Qual riso? O riso que lembra um jogo infantil, na lógica do cômico inocente ou do "cômico absoluto" de Baudelaire, aquele das crianças que é "como um desmaio de flor. É a alegria de receber, a alegria de respirar, a alegria de se abrir, a alegria de contemplar, de viver, de crescer. É uma alegria de planta." (BAUDELAIRE, 2005: 22)

No estilo decrouxiano, a comédia está muito mais vinculada ao tipo de riso que acontece diante de situações que contrariam os padrões lógicos e o bom-senso (MENDES, 2005). Ao contrário do que sugere Bergson, o riso na MCD não é aquele implicado pela noção de superioridade daquele que ri, nem de degradação do objeto, mas é aquele que se traduz pelo inusitado lembrando mais uma vez Chaplin e Molière - de um espírito travesso.

\section{Referências bibliográficas}

BAUDELAIRE, Charles. Da essência do riso - e de modo geral do cômico nas artes plásticas. Repertório Teatro \&̊ Dança. Salvador : UFBa/PPGAC, ano 8, $\mathrm{n}^{\circ}$ 8, p. 18-28, 2005.1

BERGSON, Henri. Le rire - Essai sur la signification du comique. 23a . edição, 1924. França : Ebooks libres et gratuits. Publicação eletrônica, 2005. Disponível em <http://www.ebooksgratuits.com> acessado em 09.11.2007

BENHAIM, Guy. Le style dans le mime corporel. In: PEZIN, Patrick (dir.). Étienne Decroux, mime corporel - textes, études et témoignages. Saint-Jean-deVédas: L'Entretemps éditions, 2003, p. 309-366.

DECROUX, Etienne. The origin of corporeal mime. Mime Journal. Allendale (MI), USA: The Performing Arts Center, Grand Valley States College, nos. 7\&8. p. 8-23, 1978, entrevista concedida a Thomas Leabhart. 


\section{Urdimento}

. Les dits d'Étienne Decroux. In: PEZIN, Patrick (dir.). Étienne Decroux, mime corporel - textes, études et témoignages. Saint-Jean-de-Védas: L’Entretemps éditions, 2003. p.57-209.

INNES, Christopher. Theatre after two world wars. In: BROWN, John Russel (org.). The Oxford Illustrated History of Theatre. Oxford (U.K): Oxford University Press, 1997. p 380-444.

LUST, Annette. "The Origins and Development of the Art of Mime". In: The Buffalo film seminars, 2001. Disponível em: <http://csac.buffalo.edu/enfants. pdf $>$. Acessado em 19.09.2008.

MASCARENHAS, George. A produção de sentido na mímica corporal dramatica de Etienne Decroux e na pantomima moderna. Salvador: FSBA. Diálogos possíveis. Ano 6, $\mathrm{n}^{\circ}$ 1, 2007. pgs. 69 a 79

MENDES, Cleise. O cômico: crítica e vertigem. Repertório Teatro \&̊ Dança, Salvador: Universidade Federal da Bahia, Programa de Pós Graduação em Artes Cênicas, ano 8, nº 8 p. 6- 15, 2005.

Como não falar a sério: a dança da linguagem na construção da comicidade. Revista da Bahia, Salvador: Fundação Cultural do Estado da Bahia, p. 89-96, 2006.1

WILES, David. Theatre in Roman and Christian Europe. In: BROWN, John Russel (org.). The Oxford Illustrated History of Theatre. Oxford (U.K): Oxford University Press, 1997. p. 49-92 